\title{
Pharmacological Evaluation of Green Chilli in Alzheimer's Disease
}

\author{
Pandurangan Perumal ${ }^{1, *}$ Desmond Yong Hua Chong ${ }^{2}$
}

\section{Pandurangan Perumal ${ }^{1, *}$ Desmond Yong Hua Chong $^{2}$}

\section{'Department of Pharmaceutical} Analysis, Sree Vidyanikethan College of Pharmacy, Tirupathi, Andhra Pradesh, INDIA.

${ }^{2}$ Department of Pharmaceutical Chemistry, Faculty of Pharmacy, Asian Institute of Medicine Science Technology (AIMST) University, Bedong, Kedah Darul Aman, MALAYSIA.

\section{Correspondence}

\section{Dr. Pandurangan Peruma}

Department of Pharmaceutical Analysis, Sree Vidyanikethan College of Pharmacy, Tirupathi, Andhra Pradesh, INDIA. Email id: perupharma78@gmail.com

\section{History}

- Submission Date: 22-10-2021;

- Review completed: 04-11-2021;

- Accepted Date: 02-12-2021.

\section{DOI : 10.5530/pres.14.1.10}

\section{Article Available online}

http://www.phcogres.com

\section{Copyright}

(C) 2022 Phcog.Net. This is an openaccess article distributed under the terms of the Creative Commons Attribution 4.0 International license.

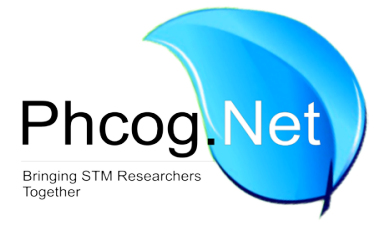

\begin{abstract}
Background: Green chilli pepper (Capsicum annum L. car frutescens) is popular as a spice used in many cuisines across the world. Capsaicin, as the pharmacologically active composition of chilli pepper, has been shown to possess antioxidant, local analgesic, and hypoglycemic effects according to many studies conducted on the red chilli pepper. However, there is no data associated with the role of green chilli peppers in Alzheimer's disease (AD) caused by capsaicin, rather than red chilli peppers. Objectives: To evaluate the acetylcholinesterase (AChE) and beta-secretase enzyme inhibition of ethanolic extract of Capsicum frutescens (EECF) or known as green chilli in in-vitro manner. Materials and Methods: Extraction was carried out on the fruits of Capsicum frutescens with ethanol. Its ethanolic extract in different concentrations was applied as the analyte to test its anti-acetylcholinesterase activity and enzymatic inhibitory action on the beta-secretase. Donepezil with various concentrations was also prepared as the control set for comparison of effect with EECF. Both the analytes were tested using the QuantiChrom ${ }^{\mathrm{TM}}$ and BACE-1 FRET assay kits, for evaluation of inhibition activity against acetylcholinesterase and BACE-1 respectively. Results: There is significant increase in the percentage of inhibition against acetylcholinesterase and BACE-1 when tested with increased concentration of EECF. Compared to inhibitory effects by EECF, donepezil exhibited higher values of $I C_{50}$ against both the assayed key enzymes, though also demonstrated vital inhibitory actions in both assays. EECF also showed higher potency in controlling $A D$ progression in terms of inhibition against acetylcholinesterase, shown by $I C_{50}$ value for the acetylcholinesterase, if compared to $I C_{50}$ value for BACE-1. Conclusion: Green chilli or EECF has potential to have inhibitory action on acetylcholinesterase and beta-secretase enzymes in patients with $A D$, but limited to optimum concentration or dose.
\end{abstract}

Key words: Alzheimer's disease, Green chilli, Betasecretase, Acetylcholinesterase, Capsaicin.

\section{INTRODUCTION}

A very common vegetable cum spice commodity that usually captures customers' attention in the agricultural market, is chilli. Chilli belongs to the family of Solanaceae (nightshades or potato family) and is classified under the genus Capsicum L. ${ }^{[1]}$ Probing further, the genus Capsicum is derived from the Greek word 'Kapsimo' which means 'to bite. Originating primarily from South and Central America, the demand for chilli is everlasting across the globe due to their attractive appearance, ability to maintain a constant sharp taste and the ease in methods employed in cultivation. ${ }^{[2]}$ Records have shown the existence of more than 200 names commonly used to identify chillies. Some of the typical terms include chilli pepper, paprika (sweet varieties), christmas pepper (ornamental), bell pepper (hot varieties) and tabasco pepper. ${ }^{[1]}$ Moreover, the genus Capsicum consists of approximately 22 wild species in which only five are referred as the domesticated species namely C. frutescens, C. chinese, C. baccatum, C. annuum and C. pubescens. ${ }^{[1]}$

\section{HISTORY}

Chilli peppers are thought to have originated in the northern Amazon basin and so, by natural geographic spread, are indigenous throughout Central America, South America, the West Indies and the most southerly states of the U.S.A. ${ }^{[3]}$ The Tepin or Chiltepin pepper (Capsicum annuum var glabriusculum) is reputed to be the oldest variety in the world and is commonly called the "Mother Chilli". The name chili was derived from the ancient Aztec dialect of Nahuatl which called the pepper chiltepin. ${ }^{[4]}$ It grows wild in northern Mexico and up into Arizona and Texas where it is now the State Chilli. ${ }^{[3]}$ It is particularly hard to domesticate but in the wild it grows best in seemingly impossible harsh habitats. In areas of extremely low rainfall, such as the Sonoran Desert, it can be found thriving in the partial shade provided by a Desert Oak or Mesquite. In these conditions, this supposedly annual plant has been known not only to survive but also to fruit for up to 20 years. ${ }^{[1,3]}$ This is an interesting feature of most chillies, if they are in conditions they like, 
they will not only thrive for several years, they will also be more prolific fruiters in their record, for the third and fourth years.

Some 5000-6000 year ago, evidence has also been found for chilli cultivation in Ecuador from around the same period. Later the Aztecs were famous for their love of chilli and it featured heavily in their diet. ${ }^{[5]}$ The ancient Inca and Aztec civilization used and worshipped the chilli. The Aztec used chilli literally in every meal and created the first chilli. The Incas worshipped the chilli as one of four mythical brothers who feature in the Incan creation. ${ }^{[3,5]}$

Chilli came into light globally when Christopher Columbus who discovered America in 1493 mistakenly thought chilli as a 'black pepper' and started the trading. The story began when Christopher Columbus encountered chillies on his first voyage to the Caribbean in 1492 and though he did not bring any back on that voyage [they were taken to Spain on his second voyage in 1495], he does write of 'a 'pepper' that the natives called 'Aji' which was better is taste and nature than ordinary peppers". ['Aji' is a Caribbean word for chillies] Wanting to prove that he had opened a new easterly route to the Indus, Columbus was keen to associate Aji with Asian "pepper". ${ }^{[5]}$

Diego Alvarez Chanca, a physician on Columbus's second voyage to the West Indies in 1493 brought the first chillies to Spain and first wrote about their medicinal qualities in 1494. From Europe chillies spread rapidly to India, China and Japan. In Europe they first were grown in the monastery gardens of Spain and Portugal as botanical curiosities but the monks experimented with their culinary potential and discovered that their pungency offered an inexpensive substitute for black pepper corns, which were so costly that they were used as legal currency in some countries. Within 50 years of its discovery the humble chillies pepper had spread across most of the then known world. ${ }^{[5,6]}$

From Spain, chilli spread to South Asian countries like India and China which spread further to Japan whereby soon chilli was accepted as an important source of spice in the local cuisines. At the initial stages, it was used only for ornamental purposes as many exotic plants then unknown but very quickly became a common food. It is assumed that the monks of the Royal Monastery of Santa Maria de Guadalupe, in Estremadura, Spain were the first European to discover the taste of hot peppers and add them to their kitchen. ${ }^{[3]}$ Originally cultivated in monasteries, seeds were then spread throughout Spain and Europe by traveller monks. ${ }^{[6]}$ It was in 1600 that through trade routes from South America. Portuguese and Spanish traders introduced the Chilli pepper in Africa, India in Asia. ${ }^{[3,6]}$ The spread of Chilli peppers to Asia was most likely a natural consequence of its introduction to Portuguese traders, who aware of its trade value would have likely promoted its commerce in the Asian spice trade routes then dominated by Portuguese and Arab traders. Today Chilies are an integral part of South Asian and South East Asian cuisine. ${ }^{[3-6]}$

Chillies or hot peppers are small fruit-vegetable that commonly used as spice and flavour in multiethnic Malaysian cuisine. Capsicum annuum is the botanical name of chilli under the family of Solanaceae. In fact, capsicums appear to be of American origin and were introduced into India at a very early date, possibly by the Portuguese. At different ripening stages, fruits of Capsicum annuum exhibit varying colour, i.e., unripe gives green, mature gives yellow and over-ripe gives red. Asian Chillies, for e.g., Bird's eye chilli, are oblong-conical in shape and the membranous dissepiment, where seeds are attached, separates fruit into two cells. The characteristic hot and pungent taste of chilli is attributed to the main active component - capsaicin (trans-8-methyl-N-vanillyl-non6 -enamide). Capsaicin is the pungent oleo-resin of the fruits of chilli, but its content is varying with varieties and stages of maturity. In 1876, Thresh extracted the compound with petroleum and treated the extract with aqueous alkali. Crystals of pungent compound, capsaicin was precipitated out by passing carbon dioxide through the alkaline liquid.
Therefore, this implied that capsaicin is a phenolic compound. ${ }^{[6]}$ Pure capsaicin when extracted out is water-insoluble, colourless, odourless and crystalline-to-waxy solid at room temperature. ${ }^{[6]}$ Capsaicin, when given internally, act on vanilloid receptors, viz. vanilloid type 1 transient receptor potential receptor (TRPV1). This binding induces inflammation reaction and irritation, so it gives hotness and burning when ingested or applied topically. Meanwhile, it desensitizes sensory nerve endings to pain stimulation by depleting the neuropeptide, substance P from local C-type nerve fibres, thus making it a local analgesic for osteoarthritis, painful diabetic neuropathy and post-herpetic neuralgia. ${ }^{[7,8]}$ In early days, capsaicin has already been used for cough and cold because its receptor was found as a sensor of airway irritation and initiator of the cough reflex. Due to its hotness characteristics, some creams or ointment containing capsaicin are intended to give counter-irritant effect, for e.g. for the relief of rheumatism, when applied externally, but it may produce severe irritation. ${ }^{[9]}$

Chilli pepper is well-known for their high Vitamin C contents (0.1-0.5\%), thus having strong antioxidant capability. Red carotenoids such as capsanthin and capsorubin, thiamine and fixed oil (4-16\%) are also present in C. annuum. The other capsaicinoids, for e.g. dihydrocapsaicin (22\%), nordihydrocapsaicin (7\%), homocapsaicin (1\%) and homodihydrocapsaicin (1\%) also account for the pungency and heat produced by chilli. They are esters of vanillyl amine with C8-C13 fatty acids. ${ }^{[10]}$ Water-soluble constituents had been.

Isolated in 1990 by Izumitani from C. annuum named capsianosides. At over-mature stage, the brilliant red colour of $C$. annuum is due to capsanthin, a tetraterpenes compound, so chilli is sometimes used as colouring agent. Many things can happen as a double-edged sword, and chilli is not an exception. Contradictory data on the mutagenic and anticarcinogenic activities of capsaicin had been obtained from many studies, as a result, there is still a lot of uncertainty in whether the use of capsaicin is totally safe. ${ }^{[11]}$ Eating too much chilli can also lead to constipation, heartburn, and even gastric cancer. ${ }^{[1,12]}$ Chilli pepper had been studied on its insulinotropic action which mainly through improving insulin resistance, but controversy on defective insulin secretion caused by capsaicin arised recently. ${ }^{[3,13]}$

A short flower stalk in an inflorescence or cluster of flowers. Pedicles hold individual flowers in place, but how they do that depends on the form of the inflorescence. The function of pedicels is to expose flowers to the sun and wind and put them in a position so their aroma and colour attracts pollinating insects more easily. An inflorescence grows from a main stem, also called a peduncle. The term "stem axis" is sometimes used instead of peduncle. ${ }^{[14-16]}$

\section{CHEMICAL CONSTITUENTS OF GREEN CHILLI}

Chillies are reported to contain an oleoresin (16\%), ascorbic acid, protein (16\% dry wt.), fat (6\% mainly in seeds), carbohydrates $(32 \%)$, carotenoids, volatile oil and Vitamin E. The oleoresin extracted by solvent yields capsaicinoids and some carotenoids. ${ }^{[8,17]}$ The most important component of capsainoids is phenlyamide capsaicin that counts for the pungency of the chilli. Other components include dehydrocapsaicin, nordihydrocapsaicin, vanilly amides of caprylic, nonylic and decyclic acids, capsiamide and homocapsaicin. ${ }^{[10,17]}$ Any variation in the chemical structures of the capsaicinoids, including the structure of the acyl moiety, affects the degree and the level of the pungency. The presence following secondary metabolites are useful in differentiating the red and green peppers. ${ }^{[17]}$

- $\quad$ Red chilli constituents: Capsanthin and capsorubin (carotenoids responsible for the red colour), $\beta$-carotene 
- Green chilli constituents: Lutein, neoxanthin, violaxanthin, $\beta$-carotene, polyphenols

The composition of capsaicin and its other associated alkaloids in dried chilli peppers is much higher than the fresh picked ones due to the present water composition as well as water-soluble phytochemicals is minimized to little or none by evaporation. As compared to red chilli peppers, green chilli peppers are more relatively healthy due to higher water content. Owing to their lower capsaicin content, the green chillies are less likely to induce internal inflammation and indigestion instead of evoking peptic ulcer, if compared to red chilli consumption. ${ }^{[18,19]}$

\section{MAJOR AILMENT OF CENTRAL NERVOUS SYSTEM- DEMENTIA}

Our human nervous system consists of a compilation of the two systems, including peripheral nervous system and central nervous system. Normally, the central nervous system is linked to and coordinated with the peripheral nervous system consisting of numerous interwining nerves. The brain is one of the key organs in our nervous system functioning as the main regulator of our memory, thoughts, feeling, and coordination of limb movements, besides the spinal cord. Once we are born to living, our human brain evolves from the tip from the longneural tube and the neural groove will bind at three to four weeks after conception process. ${ }^{[20]}$ The basic units forming our brain are the neurons. There are around eighty-six billion neurons found in the human brain always assisting in transporting the messages to the main brain via energy trans-conversion of the electrical signals possessed by the stimuli. ${ }^{[21]}$ Therefore, the complexation of the physiological functions and regulations within the nervous system brings up to millions of human beings with unpredictable thoughts and ideas. Recently, mental health is set as one of the global health priorities. In this case, several psychological and mental defects have been always taken into consideration of conducting clinical studies to explore further.

As the population age progresses, the normal activity of nervous system among the elderly would come to trends of declination as well as other metabolic functions of body systems. Due to determinant influences from the external environment and practice of the lifestyle surrounding the modern technology, health concerns especially regarding mental are recently not gaining attention from the public. However, the basic components of the nervous system will undergo degeneration and numerous problems will be aroused as a result of the destruction of the nervous system. One of the nervous ailments includes dementia.

In fact, dementia is defined as constellation of symptoms or medical conditions which slows down the normal motor functions of the nervous system. The motor functions of central nervous system include the reduced in memory accumulation, thinking abilities, language presentation and others. This motor destruction or degeneration might be causing inconveniency to the working of daily lives. Hence, this concern related to mental ailments should not be evaded or it may detonate any undesirable sudden death. In short words, dementia could be presented in distinct types and one of the most prevalent kind is definitely Alzheimer's disease.

\section{PATHOGENESIS OF ALZHEIMER'S DISEASE}

Alzheimer's disease $(\mathrm{AD})$ has been categorized as one of the most prevalent neurogenerative diseases which commonly attacks commonly the elder populations over the years. This common disease, which collaborated as one of the dementia ailments, was named after the name of one German psychiatrist Alois Alzheimer who treated Augestes Deter as the first diagnosed female patient in 1906. ${ }^{[2]}$ According to previous neurological studies, the known symptom of memory loss occurs at the age of 35 and above. ${ }^{[23]}$ Hence, the people at the earlier age as 30 and above might be susceptible to be suffered with Alzheimer type of dementia. It is surprisingly discovered that the number of victims of this $\mathrm{AD}$ is progressed with one person at every 3 seconds. By now, the real etiology for the $\mathrm{AD}$ is still unknown. In fact, this dementia ailment can be classified into early-onset $\mathrm{AD}$ and late-onset $\mathrm{AD}$. Early-onset $\mathrm{AD}$ symptoms develop between the ages of 25 and 65 whereas late-onset $\mathrm{AD}$ symptoms become apparent after $65 .{ }^{[24]}$ Both types of $\mathrm{AD}$ are typically characterized by fuzzy memory events, difficulty of remembering things including his or her own identity, having confusion and coordination difficulties.

This AD is mainly evoked by the two known hallmark pathologies, including the accumulation of undissolved peptide plaques and the formation of the neurofibrillary tangles of the microtubule protein tau. One theory known as the "amyloid cascade hypothesis" merely answers the major cause of the AD. ${ }^{[25]}$ This hypothesis had become a popular discussion topic and under associated research by the present times. The hypothesis states that the $\mathrm{AD}$ is induced by the increasing amount of one kind of decisive peptide called as amyloid-beta $(A \beta)$ deposited within the cytosol in the nervous components. This $A \beta$ peptide is produced as one of the fragmentation products of one large protein called as amyloid precursor protein (APP) by its respective enzymes, $\beta$-secretase. The binding of the APPs to the active site of $\beta$-secretase in specific sites of neurons would produce numerous amounts of smaller beta-amyloid peptides. The deposition of the $\mathrm{A} \beta$ peptides would eventually conduct next series of biochemical events inducing the destruction of the brain cells and neurons, resulting in this neurodestructive disease. ${ }^{[24,25]}$ On top of that, $\mathrm{AD}$ also progresses when the microtubule proteins tau become hyperphosphorylated. Microtubules are known to be actively in cell division process, intracellular transport and cell shape maintenance. Within most of the neurons, there are several microtubules assisting in the synaptic signal transmission to the end of the neuronal axons. The microtubule-associated protein tau is found in numerous quantities, attached on the external structure as the support and structural maintenance of the neuronal microtubules, besides assisting in the production and stabilization of the microtubules. As tau is detached from the microtubule, increasing quantities of separately undissolved tau eventually formulate lots of tau aggregates. ${ }^{[24-26]}$ If tau clearance is not successfully proceeded, this disintegrated tau aggregation will become insoluble and develop the neuronal pretangles accumulating into neurofibrillary tangles (NFT) by the phosphorylation expressed by one of the glycogen synthase kinase enzymes, GSK-3. ${ }^{[2]}$ The presence of several NFTs induces neuronal toxicity in terms of interference with normal neuronal functions, impairment of motor and cognitive functions, and also worsening neuronal degeneration. ${ }^{[24]}$ Hence, the recent studies had been conducted to formulate associated solutions against those two major pathologies mentioned above in case of all types of $\mathrm{AD}$ case events.

\section{RELATIONSHIP OF ALZHEIMER'S DISEASE WITH PRESENT STUDY}

The degeneration or functional loss of the body systems is one of the hallmarks determining the aging process due to the oxidative stress among the elderly populations. Therefore, the rapid destruction of the brain cells would also be one of the signals which resemble the oxidative stress occurring within the nervous system. Several studies had discovered that this $\mathrm{AD}$ is more associated with the diabetic risk and its hyperglycemic complications. From the previous studies, the capsaicin and its analogues were finally researched their hypoglycemic actions by stimulating the insulin secretion from the pancreas in the diabetic patients. However, the pharmacological actions of capsaicin or capsicum 
from green chilli in ADhas no relevant clinical data discovered out yet. Before the other chemicals had been identified out from the green chilli pepper sample extract which can deal with the accumulation of beta-amyloid and also lysis of ACh molecules, this can only merely be hypothesized that the composition of antioxidants like beta-carotene and ascorbic acid (Vit. C) would help combat the oxidative stress inducing $\mathrm{AD}$, and anticholinesterase potency possessed by capsaicin.

\section{MATERIALS AND METHODS}

\section{Materials}

Fresh green chilli pepper (Capsicum annuum L.varfrutescens) was purchased from thelocal market, cotton wool, ethanol (Absolute alcohol), aluminium foil.

\section{Apparatus}

Measuring cylinder, knife, electric grinder, beakers, glass rod, weighing balance, retort stands, Soxhlet Apparatus, rotary evaporator, heating mantle, 500ml round-bottomed flask, water pipe, water bath (Tuff TEB-26), china dish, conical flask.

\section{Methods}

\section{Preparation of green chilli powder}

Fresh green chilli pepper (Capsicum annuum L. varfrutescens) was purchased from the local market. Its calyx and stalk were removed, leaving the fruit part to be cut into small pieces and dried with a soft tissue before drying under the shade for one to two weeks. The dried green chilli was finely ground into powder by using an electric grinder and preserved in an air-tight container at room temperature until the preparation of experimental diets.

\section{Extraction of capsaicin \\ Soxhlet extraction}

Approximately 25g of powdered green chilli was weighed. A Soxhlet extraction tube was assembled into an apparatus with a condenser and round-bottomed boiling flask. Instead of using porous thimble, a small mass of cotton wool was placed at the bottom and top of the tube to sandwich the powdered bed added in between. Around 300ml of ethanol, along with porcelain chips was taken into the round-bottomed flask. The apparatus was placed on the heating mantle with retort stand and clamp. The cold tap water was circulated through the condenser. The solvent was made to boil to allow the siphoning cycle to take place. Therefore, extraction of capsaicin with ethanol at $70^{\circ} \mathrm{C} \pm 5^{\circ} \mathrm{C}$ was completed within three days when the extracting solvent became clear.

\section{Maceration}

Another method for extraction of capsaicin that had been attempted was maceration to achieve larger quantity of extraction. $50 \mathrm{~g}$ of powdered green chilli was weighed and placed in conical flask. Around $350 \mathrm{ml}$ of ethanol was mixed with the chilli powder. The flask was then stoppered or covered with aluminium foil to reduce the loss of solvents by evaporation. Frequent agitation was done by using the mechanical stirrer to allow homogenization of the final solution and saturation of the solvent. The whole solvent was allowed to stand at room temperature for five days with frequent agitation to allow penetration of extracting solvent into the cellular structure to dissolve the soluble compounds. After that period, the solvent was renewed again and left for another three days until the plant material was exhausted. The liquid was strained and marc was pressed. The liquid collected from first and second batch of maceration was filtered to obtain a clear extract.

\section{Rotary evaporation}

After extraction, the solvent was eliminated by rotary evaporation under reduced pressure at temperature of around $65^{\circ} \mathrm{C} \pm 3^{\circ} \mathrm{C}$ with approximately $90 \mathrm{rpm}$. The concentrated extract was obtained after few hours.

\section{Water bath}

In order to safely achieve maximum concentration of the extract, water bath was used by adding the concentrated extract into the china dishes which were placed on the water bath at temperature of $45^{\circ} \mathrm{C}$. After few days, the gummy residue from the extract was weighed and stored in the refrigerator to be used as experimental diets.

\section{IN-VITRO ACETYLCHOLINESTERASE (ACHE) EVALUATION}

The assay for measuring AChE activity was evaluated based on Ellman's method. ${ }^{[27-29]}$ The principle of this method is based on enzyme hydrolyzes the substrate acetylthiocholine iodide (ATCI) into thiocholine and acetic acid. Then, thiocholine can react with 5,5-dithio-bis-(2-nitrobenzoic acid) (DTNB) and formation of yellow color. The intensity of the color formation is directly proportional to the activity of the enzyme. Briefly, $150 \mu \mathrm{l}$ of $0.1 \mathrm{M}$ sodium phosphate buffer $(\mathrm{pH} 8.0), 10 \mu \mathrm{l}$ of the test compound, and $20 \mu \mathrm{l}$ of the enzyme solution $(0.1$ units $/ \mathrm{mL})$ were added and incubated for $15 \mathrm{~min}$ at $25^{\circ} \mathrm{C}$. After that, mixed with $10 \mu \mathrm{l}$ of DTNB $(10 \mathrm{mM})$ and $10 \mu \mathrm{l}$ of ATCI $(14 \mathrm{mM})$ to initiate the reaction, incubate for $10 \mathrm{~min}$. The color formation was measured at $410 \mathrm{~nm}$ wavelength. The controls contained the solvent to dissolve the compound instead of test compound.

The percentage inhibition for each test solution was then calculated using the following equation:

$$
\operatorname{AChE~Inhibition~}(\%)=\left(\frac{1-\text { Absorbance sample }}{\text { Absorbance control }}\right) \times 100
$$

\section{IN-VITRO BETA-SECRETASE (BACE-1) ASSAY}

Screening $\beta$-secretase inhibitors using purified enzyme ${ }^{[30]}$

Compounds at concentration ranging from $0.1-100 \mu \mathrm{g} / \mathrm{mL}$ were assayed for BACE-1 inhibition using a fluorescence resonance energy transfer (FRET) assay. This assay uses baculovirus-expressed BACE-1 and peptide substrate based on Swedish mutation of APP. The mutation dramatically enhances the cleavage of APP by BACE- 1 enzyme and this peptidic substrate becomes highly fluorescent upon enzymatic cleavage. A mixture of $10 \mu \mathrm{L}$ of test compound diluted in assay buffer, $10 \mu \mathrm{L}$ of BACE-1 substrate (Rh-EVNLDAEFK-quencher, in $50 \mathrm{nM}$ ammonium bicarbonate) and $10 \mu \mathrm{L}$ of BACE-1 enzyme $(1.0 \mathrm{U} / \mathrm{mL})$ were incubated for $60 \mathrm{~min}$ at room temperature in a dark condition. After that, $10 \mu \mathrm{L}$ of BACE- 1 stop buffer $(2.5 \mathrm{M}$ sodium acetate) was added to the mixture. The fluorescence was read by using a spectrofluorometer (TECAN) under the excitation at $545 \mathrm{~nm}$ and emission at $585 \mathrm{~nm}$. The percentage of BACE-1 inhibition was measured using the equation below:

$$
\text { BACE }-1 \text { inhibition }(\%)=\left(\frac{1-\text { Test Sample }}{\text { Positive Control }}\right) \times 100
$$

\section{STATISTICAL ANALYSIS}

Data was presented as mean \pm standard deviation (SD). All analyses were carried out intriplicates. GraphPad Prism 5 and Microsoft Excel 2007 were applied for the statistical and graphical evaluations. 


\section{RESULTS}

\section{In-vitro Acetylcholinesterase (AChE) Assay}

The assay of acetylcholinesterase was based on an improved Ellman method in a 96 well plate reader using QuantiChrom assay kit (USA). One of the characteristic changes that occur in $\mathrm{AD}$ is increase in acetylcholinesterase (AChE) activity, the enzyme responsible for acetylcholine hydrolysis, from both cholinergic and non-cholinergic neurons of the brain. The results obtained from the ethanolic extract of Capsicum frutescens (EECF) against AChE enzyme inhibition activity and the percentage inhibition was evaluated and tabulated in Tables 1 and 2 respectively. $\mathrm{IC}_{50}$ value of EECF was found to be $0.056(\mathrm{mg} / \mathrm{mL})$. However, these compounds are shown to be highly effective as compared with control AChE inhibitor donepezil $(0.096 \pm 0.030 \mu \mathrm{M} / \mathrm{mL})$.

\section{In-vitro Beta-secretase (BACE-1) Assay}

The assay of $\beta$-secretase was based on fluorescence resonance energy transfer (FRET) method using Swedish mutation of amyloid precursor protein (APP). One of the characteristic changes that occur in $\mathrm{AD}$ is increase in $\beta$-secretase enzyme (BACE-1) activity, the enzyme responsible for $\beta$-Amyloid $(A \beta)$ formed by the continuously proteolytic processing of $\beta$-amyloid precursor protein (APP) by $\beta$ - secretase and $\gamma$-secretase, plays a vital part in the pathogenesis of AD. The results obtained from the ethanolic extract of GCE against BACE-1 enzyme inhibition activity and the percentage inhibition was evaluated and tabulated in Tables 3 and 4 . The $\mathrm{IC}_{50}$ value of EECF was found to be $0.074 \pm 0.006 \mathrm{mg} / \mathrm{mL}$. However, these compounds are shown to be highly effective than control AChE inhibitor donepezil $(0.096 \pm 0.030 \mu \mathrm{M} / \mathrm{mL})$.

Table 1: The AChE inhibition of ethanolic extract of CF and control.

\begin{tabular}{cccc}
\hline $\begin{array}{c}\text { Concentration } \\
(\mathrm{mg} / \mathrm{mL}) \text { of EECF }\end{array}$ & $\begin{array}{c}\text { Percentage } \\
\text { of inhibition } \\
(\%)\end{array}$ & $\begin{array}{c}\text { Concentration } \\
(\mu \mathrm{M} / \mathrm{mL}) \text { of } \\
\text { Donepezil }\end{array}$ & $\begin{array}{c}\text { Percentage } \\
\text { of inhibition } \\
(\%)\end{array}$ \\
\hline 0.25 & $25.75 \pm 0.18$ & 0.1 & $68.38 \pm 0.14$ \\
0.5 & $61.44 \pm 0.33$ & 1 & $91.29 \pm 0.18$ \\
1 & $66.46 \pm 0.22$ & 10 & $94.09 \pm 0.19$ \\
2 & $76.30 \pm 0.30$ & 100 & $96.13 \pm 0.17$ \\
$\mathrm{IC}_{50}(\mathrm{mg} / \mathrm{mL})$ & $0.056 \pm 0.005$ & $\mathrm{IC}_{50}(\mu \mathrm{M} / \mathrm{mL})$ & $0.096 \pm 0.030$ \\
\hline
\end{tabular}

All the values are shown as mean $\pm \mathrm{SD}(n=3)$

Table 2: IC ${ }_{50}$ value of EECF and control (AChE inhibition).

\begin{tabular}{ccc}
\hline S. No & Name of the compound & IC $_{50}$ \\
\hline 1. & EECF & $0.056 \pm 0.005(\mathrm{mg} / \mathrm{mL})$ \\
2. & Donepezil & $0.096 \pm 0.030(\mu \mathrm{M} / \mathrm{mL})$ \\
\hline
\end{tabular}

Table 3: The BACE-1 inhibition of ethanolic extract of GC compared with control.

\begin{tabular}{cccc}
\hline $\begin{array}{c}\text { Concentration } \\
(\mathrm{mg} / \mathrm{mL}) \text { of EECF }\end{array}$ & $\begin{array}{c}\text { Percentage } \\
\text { of inhibition } \\
(\%)\end{array}$ & $\begin{array}{c}\text { Concentration } \\
(\mu \mathrm{M} / \mathrm{mL}) \text { of } \\
\text { Donepezil }\end{array}$ & $\begin{array}{c}\text { Percentage } \\
\text { of inhibition } \\
(\%)\end{array}$ \\
\hline 0.25 & $32.37 \pm 0.10$ & 0.1 & $68.38 \pm 0.14$ \\
0.5 & $52.37 \pm 0.09$ & 1 & $91.29 \pm 0.18$ \\
1 & $62.23 \pm 0.12$ & 10 & $94.09 \pm 0.19$ \\
2 & $69.67 \pm 0.05$ & 100 & $96.13 \pm 0.17$ \\
$\mathrm{IC}_{50}(\mathrm{mg} / \mathrm{mL})$ & $0.074 \pm 0.006$ & $\mathrm{IC}_{50}(\mu \mathrm{M} / \mathrm{mL})$ & $0.096 \pm 0.30$ \\
\hline
\end{tabular}

All the values are shown as mean $\pm \mathrm{SD}(n=3)$
Table 4: IC ${ }_{50}$ value of ethanolic extract of GC compared with control (BACE-1 inhibition).

\begin{tabular}{ccc}
\hline S. No & Name of the compound & IC $_{50}$ \\
\hline 1. & EECF & $0.074 \pm 0.006(\mathrm{mg} / \mathrm{mL})$ \\
2. & Donepezil & $0.096 \pm 0.030(\mu \mathrm{M} / \mathrm{mL})$ \\
\hline
\end{tabular}

\section{DISCUSSION}

Since Alzheimer's disease (AD) is known to be listed in one of the ten global death-leading causes, the level of study workload related to this neurodegenerative disease is continuously increasing. It is merely to track the alternative way out to manage and alleviate the major dementia symptom of AD. Basically, the studies were aimed towards the two main pathological factors, including the APP processing and cholinesterase enzymes. $^{[24]}$ Undeniably, tau phosphorylation is also linked to the pathophysiological properties of this dementia ailment, which could occur as well with the APP processing. Previously, there were several studies regarding risk of $\mathrm{AD}$ and its correlation with the capsaicin administration in in-vivo manner. ${ }^{[31-34]}$ However, the established data was merely limited to the utilization of red chilli peppers. Hence, the present study is designated for only the green chilli to estimate the inhibition potency of green chilliethanolic extracts against the AD risk in terms of enzymatic inhibition against acetylcholinesterase (AChE) and BACE- 1 , as one of the $\beta$-secretase enzymes. ${ }^{[27]}$ According to the result data regarding the inhibition activity of EECF against AChE and BACE-1 collected throughout the present study in-vitro method, EECF is indicated to establish higher significance in lowering the occurrence of $\mathrm{AD}$ by terms of presenting higher percentage of inhibition against both the AChE and BACE-1, as compared with the data of using conventional medication for such study design.

Since the study was overall conducted in in-vitro manner, the enzyme assay kits which are used in the way of having well-plate were utilized, including AChE and BACE-1assay kits. For the assay of AChE inhibition by capsaicin, one of the AChE assay kit products, i.e. QuantiChromTM assay kit was applied to determine and analyze the inhibition of AChE in quantitative manner using standard and sample analytes. BioAssay Systems QuantiChrom ${ }^{\mathrm{Tw}}$ Acetylcholinesterase Assay is based on an improved Ellman's method, which is limited for in-vitro studies. This method applies the principle based on the hydrolysis of thiocholinederivative compounds, including $\mathrm{ACh}$ and butyrylcholine (BCh), by the enzyme cholinesterases (ChEs). ${ }^{[29,35]}$ The final development of yellow colour is due to the production of the final product, i.e. 5-thio2-nitrobenzoate, and the functionality of the ChEs could be indicated according to the intensity of yellow colour observed from the well-plate of the assay kit experimental setup. ${ }^{[35]}$ The yellow colour exhibited by the final product from the reaction of thiocholine substrate and DTNB compound is due to the shifting of certain electrons from the ester linkage to one side of the nitrobenzoic acid within the DTNB while reacting to thiocholine substrate. ${ }^{[35]}$ For the part of another estimation study of BACE-1 inhibition using capsaicin, the BACE-1 Fluorescence Resonance Energy Transfer (FRET) assay kit was utilized for this study experimental in-vitro setup. ${ }^{[30,36]}$ It applies the principle of resonance energy transfer between the two-sensitizing light components; hence the darker environment is required to observe the changes. In both assay tests, the condition ofentire assay medium should also be adjusted $\mathrm{pH}$ to its respective optimum acidity and basicity as the activity of AChE and BACE- 1 is also dependent on the changes in the $\mathrm{pH}$ of the surrounding medium. ${ }^{[37,38]}$ The evaluation of anti-Alzheimer properties through AChE and BACE-1 inhibition is also applied in one previous study regarding the baicalein. ${ }^{[36]}$ 
Compared to other anti-Alzheimer drugs including galantamine, donepezil is the medication present in the market available in the lowest price ${ }^{[39]}$ However, as for the medication used to manage the AD symptoms by opposing the BACE-1 functions, it seems to have limited market of this medication group type for AD patients. Due to benefits for all stages of $\mathrm{AD}$ (i.e. mild, moderate, and severe), donepezil is merely the selected available medication applied as the control purpose for the enzymatic inhibition of $\mathrm{AChE}$ as well as BACE-1, although the inhibition against any amyloid protein cleavage enzyme is not induced. As one of the AChE inhibitor medications, donepezil has been used for management or one of the drug regimens to control the progression of $\mathrm{AD}$ risks in either early or late onset. Generally, donepezil works its therapeutic functions by binding competitively to the cleavage site of AChE with acetylcholine (ACh) transmitters, being active substrate of AChE ${ }^{[40]}$ The unbound AChE within and outside the neurons degrades the intracellular and extracellular ACh which aids in memory function into separated choline and acetate molecules. By donepezil antagonizing actions, concentration of those undegradedACh transmitters is under maintenance without any diminution or desensitization prior to undergo cholinergic transmission at the nerve terminals. For the control set (donepezil), the results obtained from the assay of its AChE and BACE-1 inhibition activity shows that the quantity of the inhibited AChE and BACE-1 exhibits a gradual increment with the consecutive increase in the concentration of the introduced donepezil.

As for the results attained from the present assay regarding the AChE inhibition activity, it could be assumed that the capsaicin from the EECG is effective in reducing the functionalities of AChE in-vitro, in terms of linear increase in the inhibition quantity of AChE with the consecutive enhance in the EECF concentration. In case, the potent inhibitory action of capsaicin against AChE may be implicated from the results obtained. Capsaicin had been discussed in previous studies regarding its anti-inflammatory and pain soothing effects upon in-vitro local site application. This is related to its affirmed binding affinity to the TRVP1 receptor, being the typical capsaicin receptor, which channels the main afferent neurons that are responsible in dealing with the pain and heat stimuli from the external surrounding. Hence, it has exhibited its specific analgesic effect that it has been applied on the manufacture of the antiinflammatory cream and ointment utilized for minimizing of pain at the local sites. In this current study, the mechanism of opposition against AChE activity was discovered to be similar as the pain mechanism mentioned above. ${ }^{[12,41,42]}$

Metabolism is known to be the essential process for all the chemicals and toxins to undergo after administration into the living system through various routes, including capsaicin itself. However, due to the complexities of its metabolism, so it is complicated to explore the mechanism of capsaicin after introduced into the system. In one previous study, Brock C. had investigated into and explained the metabolic pathway of capsaicin via various routes of administration, including in-vivo and in-vitro routes. ${ }^{[10]}$ Prior to the explanation regarding the routes of capsaicin, its physical and chemical properties were revisited to understand clearly its mechanism of pharmacokinetic routes. As discussed above, capsaicin is chemically named as trans-8-methyl-Nvanillyl-6-nonenamide, and also grouped collectively as capsaicinoids as well with nordihydrocapsaicin compound. This active component is also possessed by most of the Capsicum sp., i.e. chilli peppers, except sweet peppers or bell peppers. As the capsaicin proceeds unchanged beyond the gastric system, it would undergo biotransformation into its specific second metabolites. One of the second metabolites of capsaicin after being bio-transformed includes vanillin present in lesser quantity. ${ }^{[10]}$ The other associated major metabolites of capsaicin include 16-hydroxycapsaicin, 17-hydroxycapsaicin, and 16,17-dihydroxycapsaicin. In context to the study, it is suggested that merely little portion of capsaicin is found to be metabolized into two metabolites, i.e. vanillylamine and vanillic acid. ${ }^{[10]}$ Vanillylamine is produced as the metabolite of vanillin after enzymatic process of vanillin transferase, whereas vanillin acid being one of the plant metabolites, has also exhibited its antagonistic properties on the anionic site of AChE. Therefore, due to their presence, capsaicin within the chilli peppers is also known as one of the vanilloid compounds, which scores the highest SHU value based on the Scoville value for grading of spiciness.

$\mathrm{ACh}$, as a major small-molecule transmitter in the cholinergic system, is mainly involved in the signaling of muscular contraction. Within most of the body systems, AChtransmitters are mainly involved in normal brain and muscle functions, in terms of memory and learning abilities and the control of muscle movements and limb coordination. Moreover, the presence of ACh also takes part in most of the metabolic functions including the activation of pain sensory receptors, vasodilation on the increase in temperature stimuli, regulation of body secretion including endocrine system. ${ }^{[43]}$ Within cardiovascular and muscular systems, it also possesses its inhibitory actions at certain smooth muscles and at cardiac muscle. The excessive quantity of this cholinergic transmitters would likely to induce specific toxicities at the muscarinic and nicotinic receptors. In contrast, deficiency in ACh may be linked to prominent decline in cognitive function and also further impairment of memory function in elderly population. However, this hypothesis seems not yet to attain certain verification with strong evidence due to occurrence of the nervous symptoms related to insufficiency in ACh levels in certain brain areas has not been concluded yet and the phenomenon is also hardly determined.

Due to the lipophilic nature and its lower molecular weight, vanillin has greater potential to penetrate across the blood-brain barrier without difficulties. This has also been emphasized by one of the studies by Salau VF, et al. ${ }^{[44]}$ Therefore, it could have diffused freely within the cholinergic neurons in the certain brain areas. In case, vanillin, which has been bio-transformed from capsaicin molecule itself, is suggested to possess anti-Alzheimer property in the way of AChE inhibition. One of the studies had discovered that one of the vanillin compounds exhibited greater potential in the inhibitory action against AChE in-vitro as compared to the cinnamaldehyde compounds besides having higher antioxidant properties during the analysis of azomethines derived from these two components. ${ }^{[44,45]}$ On top of that, another causative factor contributing to $\mathrm{AD}$ is suggested to be the higher level of oxidative stress in the brain areas besides $\mathrm{AChE}$ working in the disease progression. Interestingly, certain phenolic compounds, including vanillin compound, are proclaimed to have exhibited their antioxidant potentials in $\mathrm{AD}$. It is clearly demonstrated that vanillin derived from capsaicin has possessed affirmed antioxidant property besides exhibiting its neuroprotective effect in its role of inhibiting AChE in the control or management of $\mathrm{AD}$ risk progression. ${ }^{[46-48]}$ For the part lacking, that is the dose-effect relationship of usage of vanillin in clinical trials, it is suggested to conduct related human studies regarding this arose issue.

It is known that the $\mathrm{AD}$ occurrence is also highly associated with the genetic factors, besides the aging factor, the practice of lifestyle habits which are mostly health-affecting and the previous acquired vascular diseases for especially the elderly population. One of the well-known hallmarks for this evoking of $\mathrm{AD}$ including the formation of senile plaques of $\mathrm{A} \beta$, by the two enzymes including $\beta$ - and $\gamma$-secretases. ${ }^{[25,49]}$ In case, the presence and role of BACE-1 is the prominent risk factor in the occurrence of AD. From the comparison between potencies of BACE-1 inhibition by the EECG and donepezil control sets in the present study, EECF is interpretated to exhibit that its greater potency in declining BACE-1 functionalities which is represented by increase in the 
percentage of BACE- 1 inhibition correlated with the consecutive increase in the EECF concentration. Based on the results above, capsaicin has also been suggested to have possible antagonizing effects in the accumulation of $A \beta$ plaque production within the neurons, besides having possible its associated anti-dementia benefits in the way of inhibiting AChE.

In fact, $A \beta$ peptide is one of the neuropeptides which has been emphasized in the role of boosting memory functions in normal healthy person, in the normal concentrations for the maintenance of physiological processes within the nervous system. These small-sized peptides are actually originated from the large molecular transmembrane integral protein surrounding the present neurons, known as the amyloidprecursor protein (APP) playing its role in memory and neurocognitive functions. ${ }^{[49]}$ The presence of this peptide is normally concentrated at the nerve terminals as these APP molecules are mainly discovered within the synapses between two nerve cells present in the nervous system. As the concentration of the intracellular $\mathrm{A} \beta$ peptides increases uncontrollably through abnormal reproduction, this would lead to development of $A \beta$ senile plaque due to insoluble characteristic of beta-amyloid peptides. ${ }^{[25,49]}$ Their insoluble traits further cause more clefted $A \beta$ peptides primarily by $\beta$-secretase become further saturated and eventually accumulated into irreversible plaques evoking undesired events in the nervous system of defects. Progressive accumulation of these $\mathrm{A} \beta$ plaques without monitoring will cause undeniable neuronal death due to loss of synaptic cleft functionalities. This process by BACE-1 was emphasized in the related theory known as "amyloid cascade hypothesis". ${ }^{[24]}$

Similar to capsaicin, this integral membrane protein also undergoes its vital metabolism or processing prior to its working of actual functions in the central nervous region. APP processing could take place in two opposite pathways, i.e. amyloidogenic pathway and non-amyloidogenic pathway. ${ }^{[49]}$ Both the pathways will eventually result in formation of numerous soluble peptides which aid in normal neuronal functions in the brain region. Amyloidogenic pathway emphasizes the metabolism of APP by the functional working of beta-secretase (or mainly BACE-1), eventually result in production of soluble APPs $\beta$ peptides. ${ }^{[49,50]}$ Compared to amyloidogenic pathway, non-amyloidogenic pathway occurs as the way of APP proteolysis by alpha-secretase enzyme into soluble APPs $\alpha$ peptides possessing neuroprotective properties ${ }^{[51]}$ As the age progresses, the frequency of non-amyloidogenic pathway becomes diminished due to the decline in functionalities of a-secretase enzyme in producing its complementary peptides, leading to enhance in the amyloidogenic pathway expression. ${ }^{[51]}$ As prior to dementia problem in elderly, the excessive expression of amyloidogenic pathway would lead to neurotoxicity due to formation of senile amyloid plaques via aggregation and further oligomerization of beta-amyloid peptides.

The assumption of direct inhibition of BACE-1 by capsaicin molecules itself attained limited verification with previous studies' evidence. There was also limited data regarding the molecular affinity of capsaicin to the anionic property of aspartic residue within the structure of BACE-1. Interestingly, while the exact mechanism of capsaicin upon $\mathrm{AD}$ progression is still unknown, one previous study suggested that this pungent capsaicin works its inhibitory action upon BACE-1 out via the non-amyloidogenic processing of APP proteolysis which serves to reduce the APP-amyloidogenic processing and decrease the concentrations of $\mathrm{A} \beta$ peptides. ${ }^{[51]}$ Within the non-amyloidogenic proteolysis of APP, one of the key alpha-secretases responsible in this process includes ADAM10. ${ }^{[51]}$ In case, ADAM10 can work out its exact proteolytic functions only after it is matured or being cleaved from its prodomain part. Undeniably, prior to the AD pathogenesis, the quantity of ADAM10 declines and the amyloidogenic processing progresses without homeostatic modulation by the non-amyloidogenicpathway, and the production of $A \beta$ is eventually beyond the Aa peptides. From the previous associated study, capsaicin was suggested to have enhanced the rate of ADAM10 maturation prior to precluding of $\mathrm{A} \beta$ generation. ${ }^{[50-52]}$ Through upregulation of the peroxisome proliferator-activated receptor alpha (PPARa), capsaicin administration could stimulate the expression of ADAM10 to produce more soluble alpha peptide molecules reducing AD risk. ${ }^{[51]}$ However, one of the available report data showed opposition against the above statement, indicatingamyloidogenic pathway could be enhanced by the capsaicin. ${ }^{[33,54]}$

On top of that, our current study also suggested that precluding of $A \beta$ production through BACE-1 inhibition is also linked to the activation of TRPV1 receptor, though the correlation between TRVP1 receptor stimulation and the changes in the BACE activity was opposed by one study. ${ }^{[55,56]}$ Besides this pathological process of the amyloidogenic APP processing, the typical dementia and confusion symptoms of AD may also be induced by the uncontrolled boost in blood glucose levels. One of the medical studies reported that dementia problem or AD risk is also one of the complications lead by the progression of chronic or untreated type 2 diabetes mellitus (T2DM). ${ }^{[57]}$ Several existed studies suggested the above correlation between T2DM and AD or its dementia risk. ${ }^{[57,58]}$ The suggestion is based on the theory of potential destruction occurred with high value of blood glucose levels. The previous researchers also assumed that vascular dementia or destructive brain alterations are secondary to the possible vascular blockade in brain region by accumulation of glucose within the body system. ${ }^{[57]}$ However, research work is recently conducted based on the suggested theory of the linkage between these two parameters to clarify this above relationship clearly due to the complexity of the mechanism behind this glucose dyshomeostasis in inducing cognitive loss phenomenon. Besides, one previous study related to T2DM supported our assumption by emphasizing that insulin secretion could be improved via the activation TRVP1 expressed on CGRP-containing fibers, followed by the desensitization by capsaicin introduction. The depletion in the concentration of calcitonin generelated peptide (CGRP) is verified in the improvement in the insulin secretion. ${ }^{[59]}$ In another in-vivo study, the inhibition of this vanilloid receptor which is $\mathrm{Ca}^{2+}$ ion-permeable, is also considered to be associated with decrease in amyloid-beta concentrations as well as in tau generation, as the excessive accumulation in the $\mathrm{Ca}^{2+}$ is conducted via permeation through TRVP1 receptors and other existed $\mathrm{Ca}^{2+}$ channels could lead to neuronal death as one of the hallmarks of $\mathrm{AD}$ pathophysiological phenomena. ${ }^{[54]}$ However, another study demonstrated its controversial data findings, indicating that the destruction to the gamma-oscillations in the hippocampus region could be diminished by capsaicin treatment via TRVP1 activation. ${ }^{[1]}$ In case, there are verification limitations of the study information regarding the mechanism of TRVP1 stimulation found due to the conflict of the appeared data obtained from the previous associated reports.

Instead of giving health benefits to the spicy lovers, heavy consumption of capsaicin also is discovered to induce adverse health events due to its irritating effect. ${ }^{[60]}$ Capsaicin found in most of the chilli peppers, including green chillies, is believed to cause a definite effect on normal digestion and further induce acute diarrhoea. As the TRVP1 receptor is stimulated through capsaicin administration via daily diet, the burning sensation arises from inside the body and causes irritation to the gastrointestinal tract especially ileum from the small intestine. ${ }^{[61]}$ In addition, the activation by capsaicin is translated by the brain to release endorphins to cause the spicy-lovers feeling tipsy, in order to consume more peppery and spicy meals. ${ }^{[62]}$ However, excessive consumption of capsaicin or spicy food most likely to cause nausea, vomiting and abdominal pain due to stimulation of pain receptors overlying throughout the digestive tract, rather than providing the necessary antioxidant functions to 
consumers. ${ }^{[60,61,63]}$ As for the aspect of cognitive function, one recent cohort study had revealed that heavy consumption of chilli peppers including green chilli peppers are highly linked to concurrent memory loss in elderly population, even in dementia elderly. It indicates that the consumption of excessive capsaicin dose would most likely deteriorate the memory conditions and exacerbate the cognitive functions while $\mathrm{AD}$ is still not treated. The memory declining effects could be more severe if towards population with lower body mass index (BMI) than normal healthy population. ${ }^{[63]}$ Furthermore, capsaicin in excessive dose administration is also likely to evoke impairment in hepatic function besides worsening dementia symptoms in $\mathrm{AD}$ population. ${ }^{[58]}$

\section{CONCLUSION}

Overall, the data findings from this recent study suggest that EECFin the concentrations of $1 \mathrm{mg} / \mathrm{mL}$ and $2 \mathrm{mg} / \mathrm{mL}$ possess greater antiAlzheimer effects, in the means of AChE and BACE-1 inhibition. However, the heavy or excessive consumption of capsaicin-based diet and the administration of high-dose capsaicin in various dosage forms is capable of inducing cognitive impairment in healthy population and even slimmer population. These adverse effects also most likely be induced towards the elderly including memory-declining $\mathrm{AD}$ patients. Previously, the results and findings are obtained from the studies regarding the red chilli peppers, but limited data regarding the green chilli peppers in animal and human studies could be found. Therefore, more animal studies related to the anti-Alzheimer effects of capsaicin from green chilli extracts should be carried out. Moreover, further associated work is required to unravel the mechanism of capsaicin within green chilli peppers in the declining phenomenon in the memory and cognitive functions in the elderly population, including healthy population at the age between 10 and 49 .

\section{CONFLICT OF INTEREST}

The authors declare that there is no conflict of interest.

\section{REFERENCES}

1. Barnes J, Anderson LA, Phillipson JD. Herbal medicines. $3^{\text {rd ed. } L o n d o n, ~ U n i t e d ~}$ Kingdom: Pharmaceutical Press; 2007;125-7.

2. Capsicum: Different types of bell peppers, health benefits, nutrition in red capsicum, recipes [internet]; 2020 Jun 30. Netmeds.com. Available from: https://www.netmeds.com/health-library/post/capsicum-differenttypes-of-bell-peppers-health-benefits-nutrition-in-red-capsicumrecipes\#: :text='Capsicum'\%20is\%20the\%20name\%20of,Kapto'\%20meaning \%20bite\%20or\%20swallow. [accessed Sep 24 2020].

3. Ettenberg J. A brief history of chilli peppers [internet]. Vol. 5(17); 2020. Legal Nomads [cited 1/12/2021]

4. CHILLIES MI. The prime spice - A history. IOSR J Humanit Soc Sci. 2017;22(7):32-6

5. Lam F. How chili peppers conquered the world (or at least most of it)? [internet]. The Splendid Table [cited Sep 24 2020]. Available from: https://www. splendidtable.org/story/2018/07/11/how-chili-peppers-conquered-the-world-orat-least-most-of-it.

6. Boslaugh SE. Chili (capsaicin). In: The SAGE encyclopedia of pharmacology and society; 2016

7. Fitzgerald M. Capsaicin and sensory neurons—a review. Pain. 1983;15(1-4):109-30.

8. Pawar SS, Bharude NV, Sonone SS, Deshmukh RS, Raut AK, Umarkar AR Chillies as food, spice and medicine: A perspective. Int J Pharm Biol Sci. 2011;1(3):311-8.

9. Üçeyler N, Sommer C. High-dose capsaicin for the treatment of neuropathic pain: What we know and what we need to know. Pain Ther. 2014;3(2):73-84. doi: 10.1007/s40122-014-0027-1, PMID 25069571.

10. O'Neill J, Brock C, Olesen AE, Andresen T, Nilsson M, Dickenson AH. Unravelling the mystery of capsaicin: A tool to understand and treat pain. Pharmacol Rev. 2012;64(4):939-71. doi: 10.1124/pr.112.006163, PMID 23023032.

11. Cowan MM. Plant products as antimicrobial agents. Clin Microbiol Rev. 1999;12(4):564-82. doi: 10.1128/CMR.12.4.564, PMID 10515903.

12. Basith S, Cui M, Hong S, Choi S. Harnessing the therapeutic potential of capsaicin and its analogues in pain and other diseases. Molecules. 2016;21(8):e966. doi: 10.3390/molecules21080966, PMID 27455231.

13. Panchal SK, Bliss E, Brown L. Capsaicin in metabolic syndrome. Nutrients. 2018;10(5):e630. doi: 10.3390/nu10050630, PMID 29772784.

14. Classification | USDA PLANTS [internet]. Plants. Available from: usda.gov. Available from: https://plants.usda.gov/java/ClassificationServlet? source=displ ay\&classid=CAPSI [cited 1/12/2021]

15. Chile anatomy [internet]. The Hatch Chile Store. Available from: https://hatchgreen-chile.com/pages/chile-anatomy [cited 1/12/2021].

16. What is the function of the pedicel of a flower? [internet]. Available from: Homeguides.sfgate.com. Available from: https://homeguides.sfgate.com/ function-pedicel-flower-64097.html. MD. Medicinal plants chemistry and properties. Science Publishers; 2016.

17. Krishnamurthy R, Malve MK, Shinde BM. Evaluation of capsaicin content in red and green chillies. 1999;58(8):629-30.

18. Kusnadi J, Arumingtyas EL, Mastuti R, Sari DRT. Variation of capsaicin content of local Indonesian mature green and red chilli pepper (Capsicum frutescens). Int j appl phys sci. 2017;3(1):28-32. doi: 10.20469/ijaps.3.50005-1.

19. Sadler TW. Langman's medical embryology. 13th ed. Philadelphia: Wolters Kluwer Health; 2015;306-7.

20. Voytek B. Are there really as many neurons in the human brain as stars in the Milky Way? [internet]; 2013 May 20. Scitable. Available from: https:// www.nature.com/scitable/blog/brain-metrics/are_there_really_as_many/ [cited 1/12/2021]

21. Hippius H, Neundörfer $G$. The discovery of Alzheimer's disease. Dialogues Clin Neurosci. 2003;5(1):101-8. PMID 22034141.

22. Karkare K. Alzheimer's can occur in 30s \& 40s: common signs include repeating questions, becoming suspicious of others [internet]; 2018 Oct 23. Dr. The Economic Times. Available from: https://economictimes.indiatimes.com/ magazines/panache/alzheimers-can-occur-in-30s-40s-common-signs-includerepeating-questions-becoming-suspicious-of-others/articleshow/66326477.cms [cited 1/12/2021].

23. Selkoe DJ, Hardy J. The amyloid hypothesis of Alzheimer's disease at 25 years EMBO Mol Med. 2016;8(6):595-608. doi: 10.15252/emmm.201606210, PMID 27025652.

24. Bertino JS, Lindsay DVC, et al. Pharmacogenomics: An introduction and clinical perspectives. $1^{\text {st }}$ ed. New York. US: McGraw-Hill Companies; 2013. p. 213-5.

25. Lippens G, Sillen A, Landrieu I, Amniai L, Sibille N, Barbier P, et al. Tau aggregation in Alzheimer's disease: What role for phosphorylation? Prion. 2007; 1(1):21-5. doi: 10.4161/pri.1.1.4055, PMID 19164903

26. Temviriyanukul $P$, Sritalahareuthai $V$, Jom KN, Jongruaysup $B$, Tabtimsri $S$, Pruesapan K, et al. Comparison of Phytochemicals, Antioxidant, and in vitro Anti-Alzheimer Properties of Twenty-Seven Morus spp. Cultivated in Thailand. Molecules. 2020;25(11):e2600. doi: 10.3390/molecules25112600, PMID 32503261.

27. Perumal $P$, Vasudevan $M$. Acetylcholinesterase and beta secretase inhibitor: Design, synthesis and characterization and evaluation. Drug Invent Today. 2020;13(9):1-7.

28. Ellman GL, Courtney KD, Andres V, Featherstone RM. A new and rapid colorimetric determination of acetylcholinesterase activity. Biochemical Pharmacology. 1961;7(2):88-95. doi: 10.1016/0006-2952(61)90145-9.

29. Parasuraman P, Suresh R, Perumal P, Vasudevan M. Synthesis of piperidine-4one derivative containing dipeptides: An AChE and $\beta$-secretase inhibitor. AntiInfect Agents. 2020;18(2):160-8.

30. Chen L, Huang Z, DuY, Fu M, Han H, WangY, et al. Capsaicin attenuates amyloid$\beta$-induced synapse loss and cognitive impairments in mice. J Alzheimers Dis. 2017:59(2):683-94. doi: 10.3233/JAD-170337, PMID 28671132.

31. Buck SH, Walsh JH, Davis TP, Brown MR, Yamamura HI, et al. Characterization of the peptide and sensory neurotoxic effects of capsaicin in the guinea pig. J Neurosci. 1983;3(10):2064-74. doi: 10.1523/JNEUROSCI.03-10-02064.1983, PMID 6194277.

32. Shalaby MA, Nounou HA, Deif MM. The potential value of capsaicin in modulating cognitive functions in a rat model of streptozotocin-induced Alzheimer's disease. Egypt J Neurol Psychiatry Neurosurg. 2019;55(1):e48. doi: 10.1186/s41983-019-0094-7.

33. Duckles SP, Levitt B. Specificity of capsaicin treatment in the cerebral vasculature. Brain Res. 1984;308(1):141-4. doi: 10.1016/0006-8993(84)90925-9, PMID 6478198

34. Pohanka M, Hrabinova M, Kuca K, Simonato JP. Assessment of acetylcholinesterase activity using indoxylacetate and comparison with the standard Ellman's method. Int J Mol Sci. 2011;12(4):2631-40. doi: 10.3390/ ijms12042631, PMID 21731462

35. Han J, Ji Y, Youn K, Lim G, Lee J, Kim DH, Jun M. Baicalein as a potential inhibitor against BACE1 and AChE: mechanistic comprehension through in vitro and computational approaches. Nutrients. 2019;11(11):e2694. doi: 10.3390/ nu11112694, PMID 31703329

36. Komersová A, Kovárová M, Komers K, Lochar V, Cegan A. Why is the hydrolytic activity of acetylcholinesterase $\mathrm{pH}$-dependent? Kinetic study of acetylcholine and acetylthiocholine hydrolysis catalyzed by acetylcholinesterase from electric 
eel. Zeitschrift für Naturforschung C. 2018;73(9-10):345-51. doi: 10.1515/znc2017-0134.

37. Ellis $\mathrm{CR}$, Shen J. PH-dependent population shift regulates BACE1 activity and inhibition. J Am Chem Soc. 2015;137(30):9543-6. doi: 10.1021/jacs.5b05891, PMID 26186663

38. Cacabelos R, Martínez-Bouza R. Genomics and pharmacogenomics of dementia CNS Neurosci Ther. 2011;17(5):566-76. doi: 10.1111/j.1755-5949.2010.00189.x, PMID 20718828.

39. Mezeiova E, Spilovska K, Nepovimova E, Gorecki L, Soukup O, Dolezal R, et al. Profiling donepezil template into multipotent hybrids with antioxidant properties. J Enzyme Inhib Med Chem. 2018;33(1):583-606. doi: 10.1080/14756366.2018.1443326, PMID 29529892.

40. Balleza-Tapia H, Crux S, Andrade-Talavera Y, Dolz-Gaiton P, Papadia D, Chen G, et al. TrpV1 receptor activation rescues neuronal function and network gamma oscillations from $A \beta$-induced impairment in mouse hippocampus in vitro. eLife. 2018;7(7):e37703. doi: 10.7554/eLife.37703, PMID 30417826.

41. Sharma SK, Vij AS, Sharma M. Mechanisms and clinical uses of capsaicin. Eur J Pharmacol. 2013:720(1-3):55-62. doi: 10.1016/j.ejphar.2013.10.053, PMID 24211679

42. Agarwal P, Alok S, Fatima A, Singh PP. Herbal remedies for neurodegenerative disorder (Alzheimer's disease): A review. 2013;4(9):3328-40.

43. Salau VF, Erukainure OL, Ibeji CU, Olasehinde TA, Koorbanally NA, Islam MS Vanillin and vanillic acid modulate antioxidant defense system via amelioration of metabolic complications linked to $\mathrm{Fe} 2+$-induced brain tissues damage. Metab Brain Dis. 2020;35(5):727-38. doi: 10.1007/s11011-020-00545-y, PMID 32065337.

44. Chigurupati S, Selvaraj M, Mani V, Mohammad JI, Selvarajan KK, Akhtar SS, et al. Synthesis of azomethines derived from cinnamaldehyde and vanillin: In vitro aetylcholinesterase inhibitory, antioxidant and in silico molecular docking studies. Med Chem Res. 2018;27(3):807-16. doi: 10.1007/s00044-017-2104-6.

45. Mukherjee PK, Kumar V, Mal M, Houghton PJ. Acetylcholinesterase inhibitors from plants. Phytomedicine. 2007;14(4):289-300. doi: 10.1016/j. phymed.2007.02.002, PMID 17346955.

46. Olatunji TL, Afolayan AJ. Comparative quantitative study on phytochemical contents and antioxidant activities of Capsicum annuum L. and Capsicum frutescens L. Sci World J. 2019;2019:1-13. doi: 10.1155/2019/4705140.

47. Rathee P, Chaudhary H, Rathee S, Rathee D. Natural memory boosters. Pharmacogn Rev. 2008;2(4):e249.

48. O'Brien RJ, Wong PC. Amyloid precursor protein processing and Alzheimer's disease. Annu Rev Neurosci. 2011:34:185-204. doi: 10.1146/annurevneuro-061010-113613, PMID 21456963.

49. Kojro E, Fahrenholz F. The non-amyloidogenic pathway: Structure and function of $\alpha$-secretases. Subcell Biochem. 2005;38:105-27. doi: 10.1007/0-387-232265_5, PMID 15709475

50. Wang J, Sun BL, Xiang Y, Tian DY, Zhu C, Li WW, et al. Capsaicin consumption reduces brain amyloid-beta generation and attenuates Alzheimer's diseasetype pathology and cognitive deficits in APP/PS1 mice. Transl Psychiatry. 2020;10(1):230. doi: 10.1038/s41398-020-00918-y, PMID 32661266.

51. Endres K, Deller T. Regulation of alpha-secretase ADAM10 in vitro and in vivo: Genetic, epigenetic, and protein-based mechanisms. Front Mol Neurosci.
2017;10:56. doi: 10.3389/fnmol.2017.00056, PMID 28367112

52. Pákáski $M$, Hugyecz $M$, Sántha $P$, Jancsó $G$, Bjelik $A$, Domokos $A$, et al Capsaicin promotes the amyloidogenic route of brain amyloid precursor protein processing. Neurochem Int. 2009;54(7):426-30. doi: 10.1016/j. neuint.2009.01.012, PMID 19428784.

53. Grimm MOW, Blümel T, Lauer AA, Janitschke D, Stahlmann C, Mett J, et al. The impact of capsaicinoids on APP processing in Alzheimer's disease in SHSY5Y cells. Sci Rep. 2020;10(1):9164. doi: 10.1038/s41598-020-66009-6, PMID 32514053.

54. Kim J, Lee S, Kim J, Ham S, Park JHY, Han S, et al. Ca ${ }^{2+}$ permeable TRPV1 pain receptor knockout rescues memory deficits and reduces amyloid- $\beta$ and tau in a mouse model of Alzheimer's disease. Hum Mol Genet. 2020;29(2):228-37. doi: 10.1093/hmg/ddz276, PMID 31814000.

55. Wang X, Kim JR, Lee SB, Kim YJ, Jung MY, Kwon HW, et al. Effects of curcuminoids identified in rhizomes of Curcuma longa on BACE-1 inhibitory and behavioral activity and lifespan of Alzheimer's disease Drosophila models. BMC Complement Altern Med. 2014;14:88. doi: 10.1186/1472-6882-14-88, PMID 24597901.

56. Diabetes and Alzheimer's linked [internet]; 2019 May 22. Mayo Clinic.org. Available from: https://www.mayoclinic.org/diseases-conditions/type-2-diabetes/ in-depth/diabetes-andalzheimers/art20046987\#: :text=Diabetes \% 20is \% 20 considered \%20a\%20risk,Alzheimer's \%20disease \%20and \%20vascular\% 20 dementia [cited 1/12/2021].

57. Perumal $P$, Parasuraman S. Tee SC, ling YL. Pharmacological evaluation of green chilli induced diabetes. Drug Invent Today. 2019;2019(11 (1)):10-20.

58. Wharton J, Gulbenkian S, Mulderry PK, Ghatei MA, McGregor GP, Bloom SR, et al. J Auton Nerv Syst. 1986;16(4):289-309. doi: 10.1016/0165-1838(86)90035-4, PMID 2427561

59. Mózsik G, Vincze A, Szolcsányi J. Four response stages of capsaicinsensitive primaryafferent neurons to capsaicin and its analog: gastric acid secretion, gastric mucosal damage and protection. J Gastroenterol Hepatol. 2001;16(10):1093-7. doi: 10.1046/j.1440-1746.2001.02598.x, PMID 11686834.

60. Brown K. Why eating spicy food can give you diarrhea [internet]; 2020 Feb 8. very well health. Available from: https://www.verywellhealth.com/why-doesspicy-food-cause-diarrhea-1088717 [cited 1/12/2021]

61. Wong K. Why spicy food makes you feel high [internet]; 2017 Jan 13 Lifehacker. Available from: https://lifehacker.com/why-spicy-food-makes-youfeel-high-1791090210\#: : :text=Capsaicin \% 2C\%20the \% 20compound \% 20 that $\% 20$ makes, people $\% 20$ feel $\% 20$ buzzed $\% 20$ or $\% 20$ high. \&text=As $\% 20$ a \%20response \% 2C\%20your \%20brain,P\%2C\%20which\%20transmits \% 20 pain $\% 20$ signals [cited 1/12/2021].

62. Loizzo MR, Tundis R, Menichini F, Statti GA, Menichini F. Influence of ripening stage on health benefits properties of Capsicum annuum var. acuminatum L. in vitro studies. J Med Food. 2008;11(1):184-9. doi: 10.1089/jmf.2007.638, PMID 18361755

63. Shi Z, El-Obeid T, Riley M, Li M, Page A, Liu J. High chili intake and cognitive function among 4582 adults: an open cohort study over 15 years. Nutrients. 2019;11(5):1183. doi: 10.3390/nu11051183, PMID 31137805.

\section{SUMMARY}

There is limited data related to pharmacological properties of green chilli peppers in the memory enhancing effects in $\mathrm{AD}$, although many study reports regarding the effects of red chilli peppers in $\mathrm{AD}$ are found in either in-vivo or in-vitro manner. Due to difference in the capsaicin content present between red and green chilli peppers, the present study was designed to evaluate the anti-Alzheimer effect through inhibition of AChE and BACE-1, and in order to test its potentials with red chilli peppers. The experiment setup was conducted in-vitro, using the application of AChE and BACE-1 assay kits. Besides, donepezil medication was prepared as the control set to compare the anticholinesterase and BACE inhibition potential with the various concentrations of EECF in the in-vitro setup. As for the assay using BACE-1 kit, the experiment was carried out in a dark environment without any distraction of other light sources. The results were observed in the well-plate of both the kits and the absorbance of colour formation and fluorescence, in AChE and BACE-1 kits respectively was also measured. The absorbance of fluorescence in BACE-1 assay was measured by using spectrofluorometer. From the result data obtained, EECF have greater potential in associated control and management of $A D$, in terms of its anticholinesterase effects on AChE and inhibitory actions on BACE-1. However, the consumption of green chilli peppers in excess amounts is not recommended, especially for elderly. 
GRAPHICAL ABSTRACT

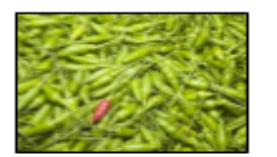

EECF extract

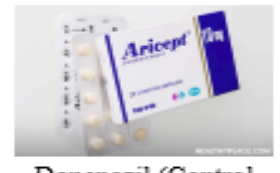

Donepezil (Control

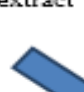

.

set)

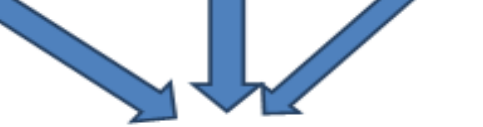

1. AChE Inhibition

2. B-secretase Inhibition

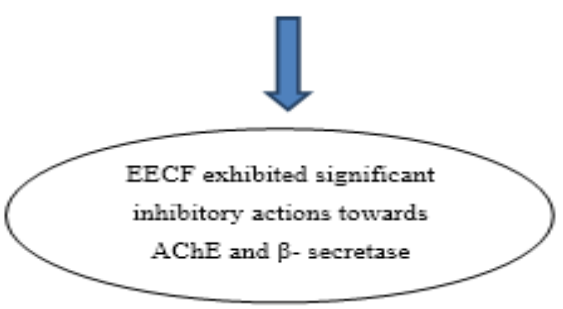

\section{ABOUT AUTHORS}

Prof. P Perumal is currently working as HOD and Research Coordinator in Sree Vidyanikethan College of Pharmacy, Tirupathi, Andhra Pradesh, India.

Desmond Yong Hua Chong is the Previous student of the corresponding author when he was in Malaysia.

Cite this article: Perumal P, Chong DYH. Pharmacological Evaluation of Green Chilli in Alzheimer's Disease. Pharmacog Res. 2022;14(1):61-70. 